\title{
Production of interleukin-8, RANTES and MCP-1 in intrinsic and extrinsic asthmatics
}

\author{
S.G. Folkard*, J. Westwick**, A.B. Millar*
}

Production of interleukin-8, RANTES and MCP-1 in intrinsic and extrinsic asthmatics. S.G. Folkard, J. Westwick, A.B. Millar

ABSTRACT: The aim of this study was to determine the relative production of chemokines interleukin-8 (IL-8), regulated on activation, normal T-cell expressed and secreted (RANTES) and monocyte chemotactic protein-1 (MCP-1) by intrinsic and extrinsic asthmatics.

Nine intrinsic asthmatics, 10 extrinsic asthmatics, five nonatopic and five atopic controls underwent bronchoalveolar lavage (BAL). Total BAL cells were cultured in the presence or absence of lipopolysaccharide. Chemokines were measured in BAL cell supernatants and in cell-free bronchoalveolar lavage fluid (BALF) by enzyme-linked immunoabsorbent assay (ELISA). BAL cell cytospins were stained immunohistochemically for chemokines.

BAL cells from asthmatics produced more IL-8 than controls (statistically significant for extrinsic asthma). RANTES was elevated in the BAL cell supernatants of four out of nine intrinsic asthmatics as compared to nonatopic controls (not statistically significant). RANTES levels in the BAL cell supernatants of extrinsic asthmatics were all low. MCP-1 production by BAL cells was similar in all groups. Immunostaining of BAL cell cytospins showed the macrophage to be the predominant positive-staining cell type and correlated well with supernatant data. Measurement of chemokines in BALF showed significantly elevated IL-8 in intrinsic asthma compared to nonatopic controls, but no increase in extrinsic asthmatics relative to atopic control RANTES was elevated in three out of nine BALFs from intrinsic asthmatics compared with nonatopic controls (not statistically significant). MCP-1 was not elevated above control levels in BALF of either asthma group.

These results suggest an up-regulation in the production of interleukin-8 and regulated on activation, normal T-cell expressed and secreted, but not monocyte chemotactic protein-1 (MCP-1), by macrophages in the bronchoalveolar lavage of asthmatic subjects. In addition, the data suggest that regulated on activation, normal T-cell, expressed and secreted, may be differentially produced by macrophages in atopic and nonatopic asthma.

Eur Respir J 1997; 10: 2097-2104.

\begin{abstract}
* Lung Research Group, University of Bristol, Division of Medicine, Dept of Hospital Medicine, Southmead Hospital, Westbury on Trym, Bristol, UK. **School of Pharmacology, University of Bath, Claverton Down, Bath, UK.
\end{abstract}

Correspondence: A.B. Millar

Lung Research Group

University of Bristol

Division of Medicine

Dept of Hospital Medicine

Southmead Hospital

Bristol BS10 5NB

UK

Keywords: Bronchoalveolar lavage

chemokine

extrinsic asthma

intrinsic asthma

macrophage

Received: October 221996

Accepted after revision May 121997

This work was supported by the Wellcome Trust.
Asthma is an inflammatory disease of the lungs that is typically characterized by an increased influx of eosinophils [1]. The recruitment and activation of other leucocytes such as macrophages [2] and T-lymphocytes $[3,4]$ has also been described. The association of asthma with atopy (extrinsic asthma) is common, however, there are cases of asthma that occur in the apparent absence of any specific atopic responses (intrinsic asthma) $[5,6]$. Studies of T-lymphocytes and cytokines in the bronchoalveolar lavage (BAL) and peripheral blood support the view that the immunological mechanisms underlying intrinsic and extrinsic asthma may differ. The differential expression of two key cytokines, interleukin (IL)-4 and interferon-gamma (IFN- $\gamma$ ) [7, 8], the activation marker human leucocyte antigen (HLA-DR), and the adhesion molecule VLA-4 [9] by T-lymphocytes have all been demonstrated between intrinsic and extrinsic asthma. Furthermore, CD8+ T-lymphocytes have been shown to be increased in the airways of intrinsic asthmatics, but not in the airways of extrinsic asthmatics [7], suggesting the presence of a selective recruitment mechanism for T-lymphocyte subsets between these two types of asthma.

We hypothesize that the previously observed differences in the selective recruitment of leucocyte populations to the lungs in intrinsic and extrinsic asthma might reflect the production of chemotactic cytokines in the airways of asthmatic individuals. The chemokines are a group of small chemotactic cytokines that share a high level of sequence homology [10], and were initially divided into two major subfamilies, $\alpha$ and $\beta$, depending upon their differential attraction for monocytes and neutrophils. Thus, the $\alpha$ chemokines, typified by IL- 8 , attracted neutrophils, while the $\beta$ chemokines, such as regulated on activation, normal T-cell expressed and secreted (RANTES) and monocyte chemotactic protein1 (MCP-1) had preferential attraction for monocytes. Subsequently, each of these chemokines have been shown 
to attract various T-lymphocyte populations [11-14]. The $\beta$ chemokines are of further interest in asthma because of a wider repertoire of effects upon those cell populations normally associated with asthma and allergic responses, namely eosinophils and basophils [15]. IL-8, RANTES and MCP-1 have all been implicated in inflammatory disorders. The up-regulation of IL- 8 by macrophages [16] and MCP-1 airways epithelium [17] in extrinsic asthmatic airways has also been described recently, and RANTES remains highly suspected of a major role in asthma, chiefly because of its potent chemotactic effect upon eosinophils [18].

In this study, we chose to investigate the production of IL-8, RANTES and MCP-1 by total BAL cells from intrinsic and extrinsic asthmatic subjects. Total BAL cells were used in order to reflect the cellular composition present in the airways in vivo. The majority of cells obtained by BAL were macrophages. Comparisons were made of chemokine protein levels in culture supernatants of total BAL cells and in cell-free BAL fluid (BALF) by enzyme-linked immunosorbent assay (ELISA), and by immunohistochemical staining of total BAL cell cytospins. Results from intrinsic and extrinsic asthmatics were compared with nonatopic and atopic controls, respectively.

\section{Materials and methods}

\section{Subjects}

Nine intrinsic asthmatics, 10 extrinsic asthmatics, five atopic controls and five nonatopic controls were recruited into this study. Asthma was diagnosed according to American Thoracic Society (ATS) guidelines [19]. Asthma severity was determined by the Aas score [20]. Subjects reported no upper respiratory tract infection in the month prior to investigation. Atopy was defined by skinprick tests to eight common allergens (Bencard, Welwyn Garden City, Herts, UK), and a positive history. Immunoglobulin $\mathrm{E}$ (IgE) antibody was measured in all subjects. Details are given in table 1 .

\section{Bronchoalveolar lavage}

Fibreoptic bronchoscopy and BAL were performed according to ATS guidelines [21]. Subjects were injected intramuscularly with $600 \mu \mathrm{g}$ atropine and sedated with $0-2 \mathrm{mg}$ alfentanil and $0-10 \mathrm{mg}$ midazolam intravenously. Topical lignocaine was administered to anaesthetize the upper airway. BAL was performed by the instillation of four $60 \mathrm{~mL}$ aliquots of sterile $0.9 \%$ saline supplemented with $0.05 \%$ sodium bicarbonate (Baxter Health Care, Thetford, Norfolk, UK) into the right middle lobe. Each instillation was followed by gentle aspiration into a siliconized bottle kept on ice.

\section{$B A L$ cells and BAL fluid}

The total BAL collected was strained through coarse gauze to remove mucus clumps and the filtrate was centrifuged $(500 \times \mathrm{g}$ for $5 \mathrm{~min}$ at room temperature) to pellet the BAL cells. Cell-free BALF (unconcentrated) was aspirated and stored in aliquots at $-70^{\circ} \mathrm{C}$. BAL cells were then washed in RPMI 1640 medium (Gibco, Paisley, UK) supplemented with antibiotics $\left(100 \mathrm{U} \cdot \mathrm{mL}^{-1}\right.$ peni- cillin and $100 \mu \mathrm{g} \cdot \mathrm{mL}^{-1}$ streptomycin, Gibco) and fungizone $\left(0.5 \mu \mathrm{g} \cdot \mathrm{mL}^{-1}, \mathrm{Gibco}\right)$. Viability of cells, assessed by trypan blue dye exclusion, was $>98 \%$ in all cases. Cytospins were prepared from a small aliquot of BAL cells and stored wrapped in aluminium foil at $-70^{\circ} \mathrm{C}$ for immunostaining. Differential cell counts were performed on remaining total BAL cells (referred to hereafter as BAL cells), which were then washed and resuspended to a concentration of $10^{6}$ macrophages $\cdot \mathrm{mL}^{-1}$ in fresh supplemented RPMI medium. BAL cells were cultured for $24 \mathrm{~h}$ at $37^{\circ} \mathrm{C}$ and $5 \% \mathrm{CO}_{2}$ in the presence or absence of bacterial lipopolysaccharide (LPS; Sigma, Poole, Dorset, $\mathrm{UK}$; at $0,0.1,1$ and $\left.10 \mu \mathrm{g} \cdot \mathrm{mL}^{-1}\right)$. Supernatants were harvested and stored at $-70^{\circ} \mathrm{C}$ until required. BAL recoveries and differential cell counts for each group are presented in table 2 .

\section{Enzyme-linked immunosorbent assay (ELISA)}

Polyclonal and monoclonal antibodies to IL-8, RANTES, MCP-1, and recombinant standards were obtained from R\&D Systems Europe Ltd (Abingdon, UK). Polyclonal antibodies were biotinylated and used as detecting antibodies. ELISA plates (Nunc maxisorb; Gibco) were coated with $50 \mu \mathrm{L}$ of monoclonal antibody $\left(1 \mu \mathrm{g} \cdot \mathrm{mL}^{-1}\right.$ for IL-8 and RANTES, $2 \mu \mathrm{g} \cdot \mathrm{mL}^{-1}$ for $\mathrm{MCP}-1$ ) diluted in carbonate buffer, $\mathrm{pH} 9.6$, overnight at $4^{\circ} \mathrm{C}$. Plates were washed with phosphate-buffered saline (PBS) containing $0.1 \%$ Tween 20, and blocked for $1 \mathrm{~h}$ at $37^{\circ} \mathrm{C}$ with $200 \mu \mathrm{L}$ of PBS containing $10 \%$ foetal calf serum (FCS; Gibco). Plates were washed again, and $50 \mu \mathrm{L}$ of samples and standards added for 2 $\mathrm{h}$ at $37^{\circ} \mathrm{C}$. After washing, $50 \mu \mathrm{L}$ of biotinylated polyclonal antibody $\left(1 \mu \mathrm{g} \cdot \mathrm{mL}^{-1}\right.$ for IL-8 and RANTES, 2 $\mu \mathrm{g} \cdot \mathrm{mL}^{-1}$ for MCP-1) diluted in wash buffer was added for $1 \mathrm{~h}$ at $37^{\circ} \mathrm{C}$. Plates were washed, and $100 \mu \mathrm{L}$ of streptavidin-alkaline phosphatase, diluted $1 / 200$ in wash buffer, was added for $30 \mathrm{~min}$ at $37^{\circ} \mathrm{C}$. After a final wash, $100 \mu \mathrm{L}$ of alkaline phosphatase substrate (Sigma) was added for approximately $1 \mathrm{~h}$ in the dark. Plates were read on a Dynatech plate reader Dynatech, Billinghurst, Sussex, UK) set to an optical density of $410 \mathrm{~nm}$. Data were extracted using a standard curve sigmoidal plot with tails. The sensitivity of each chemokine ELISA was $20 \mathrm{pg} \cdot \mathrm{mL}^{-1}$.

Total plasma IgE was measured by ELISA (Wessex Immunology Laboratories, Tenovus Building, Southampton University Hospital, UK). The sensitivity of the ELISA was $5 \mathrm{IU} \cdot \mathrm{mL}^{-1}$. The normal level of IgE for adults (aged $>15$ yrs) was calculated as the geometric mean plus one standard deviation $\left(=81 \mathrm{IU} \cdot \mathrm{mL}^{-1}\right)$.

\section{Immunohistochemical staining of BAL cell cytospins}

The following procedures were carried out in humid boxes:

IL-8 and MCP-1. IL-8 and MCP-1 were detected using polyclonal rabbit antibody (courtesy R.M. Strieter, University of Michigan, USA), and following the method of PAINE et al. [22] with minor modifications. Cytospins were allowed to thaw wrapped in foil, and were then fixed in 1:1 acetone:methanol for $90 \mathrm{~s}$, followed by a wash in tris-buffered saline (TBS) for $5 \mathrm{~min}$. Slides were blocked for $2 \mathrm{~h}$ at $37^{\circ} \mathrm{C}$ with $2 \%$ normal goat 
Table 1. - Subject details, forced expiratory volume in one second (FEV1), asthma severity (Aas score), allergen sensitivity and medication, for subjects with intrinsic or extrinsic asthma and for nonatopic and atopic controls

\begin{tabular}{|c|c|c|c|c|c|c|c|c|}
\hline Subjects & Sex & $\begin{array}{l}\text { Age } \\
\text { yrs }\end{array}$ & $\begin{array}{l}\text { FEV1 } 1 \\
\% \text { pred }\end{array}$ & $\begin{array}{c}\mathrm{FEV} 1 \\
\% \text { reversibility }\end{array}$ & $\begin{array}{l}\text { Aas } \\
\text { score }\end{array}$ & $\begin{array}{c}\text { Total } \\
\text { IgE IU } \cdot \mathrm{mL}^{-1}\end{array}$ & $\begin{array}{c}\text { Positive skin } \\
\text { allergens }\end{array}$ & $\begin{array}{l}\text { Medication } \\
\text { (daily dose } \mu \mathrm{g} \text { ) }\end{array}$ \\
\hline \multicolumn{9}{|c|}{ Intrinsic asthma } \\
\hline $1 *$ & M & 60 & 50 & 25 & 2 & 70 & None & Sal/BDP (400) \\
\hline 2 & $\mathrm{~F}$ & 56 & 85 & 20 & 1 & 141 & None & None \\
\hline 3 & $\mathrm{~F}$ & 47 & 87 & 15 & 1 & 12 & None & None \\
\hline 4 & M & 48 & 97 & 15 & 2 & 35 & None & Sal/BDP (250) \\
\hline 5 & $\mathrm{~F}$ & 35 & 76 & 25 & 1 & $<5$ & None & None \\
\hline 6 & M & 49 & 75 & 30 & 1 & 35 & None & None \\
\hline 7 & $\mathrm{~F}$ & 68 & 76 & 32 & 2 & 60 & None & $\begin{array}{c}\text { Sal/BDP (1500)/ } \\
\text { Salm (400)/PRED (10) }\end{array}$ \\
\hline 8 & $\mathrm{~F}$ & 68 & 80 & 24 & 1 & 155 & None & Sal/BDP (400) \\
\hline 9 & $\mathrm{~F}$ & 53 & 97 & 15 & 1 & $<5$ & None & None \\
\hline \multicolumn{9}{|c|}{ Extrinsic asthma } \\
\hline 10 & $\mathrm{~F}$ & 51 & 88 & 25 & 1 & 14 & $\mathrm{~F}$ & None \\
\hline 11 & $\mathrm{~F}$ & 34 & 91 & 15 & 1 & $<5$ & $\mathrm{C} / \mathrm{G} / \mathrm{HDM} / \mathrm{T}$ & None \\
\hline 12 & $\mathrm{~F}$ & 50 & 92 & 15 & 1 & $<5$ & $\mathrm{C} / \mathrm{HDM}$ & None \\
\hline 13 & M & 21 & 100 & 15 & 2 & 275 & F/HDM & Sal \\
\hline 14 & M & 23 & 103 & 15 & 2 & 750 & $\mathrm{C} / \mathrm{D} / \mathrm{G} / \mathrm{HDM}$ & Sal \\
\hline 15 & M & 28 & 98 & 18 & 1 & 29 & G & Sal \\
\hline 16 & $\mathrm{~F}$ & 42 & 73 & 30 & 1 & 270 & HDM & Sal \\
\hline $17 *$ & $\mathrm{~F}$ & 38 & 75 & 35 & 1 & 54 & D/HDM & None \\
\hline 18 & M & 21 & 105 & 23 & 2 & 30 & $\mathrm{C} / \mathrm{D} / \mathrm{G} / \mathrm{HDM} / \mathrm{T}$ & Sal \\
\hline 19 & $\mathrm{~F}$ & 36 & 8 & 20 & 2 & 43 & HDM & Sal \\
\hline \multicolumn{9}{|c|}{ Nonatopic control } \\
\hline 20 & $\mathrm{~F}$ & 28 & 98 & N/A & N/A & 14 & None & None \\
\hline 21 & M & 31 & 105 & N/A & N/A & 9 & None & None \\
\hline 22 & $\mathrm{M}$ & 51 & 101 & N/A & N/A & 11 & None & None \\
\hline 23 & M & 26 & 120 & N/A & N/A & 39 & None & None \\
\hline 24 & M & 21 & 90 & N/A & N/A & $<5$ & None & None \\
\hline \multicolumn{9}{|c|}{ Atopic control } \\
\hline 25 & M & 24 & 104 & N/A & N/A & 75 & HDM/T & None \\
\hline 26 & $\mathrm{~F}$ & 22 & 103 & N/A & N/A & $<5$ & W & None \\
\hline 27 & M & 24 & 100 & N/A & N/A & 102 & e/G/HDM & None \\
\hline 28 & $\mathrm{~F}$ & 29 & 84 & N/A & N/A & $<5$ & A/C/D/G/HDM/T/W & None \\
\hline 29 & $\mathrm{M}$ & 22 & 128 & N/A & N/A & 367 & $\mathrm{C} / \mathrm{D} / \mathrm{HDM} / \mathrm{T}$ & None \\
\hline
\end{tabular}

$\%$ pred: percentage of predicted value. M: male; F: female; Sal: salbutamol; BDP: beclamethasone dipropionate; Salm: salmeterol; Pred: prednisolone; F: feathers; C: cat; G: glass; HDM: house dust mite; D: dog; T: trees; W: weeds; A: Aspergillus; N/A: not applicable. * smokers.

Table 2. - Bronchoalveolar lavage (BAL) details for subjects with intrinsic or extrinsic asthma, and for nonatopic and atopic controls

\begin{tabular}{lccccccc}
\hline & $\begin{array}{c}\text { Total BAL } \\
\text { volume } \\
\mathrm{mL}\end{array}$ & $\begin{array}{c}\text { Total BAL } \\
\text { cells } \\
\mathrm{n} \times 10^{6}\end{array}$ & $\begin{array}{c}\text { Macrophages } \\
\text { N }\end{array}$ & $\begin{array}{c}\text { Neutrophils } \\
\%\end{array}$ & $\begin{array}{c}\text { Eosinophils } \\
\%\end{array}$ & $\begin{array}{c}\text { Lymphocytes } \\
\%\end{array}$ & $\begin{array}{c}\text { Epithelial } \\
\text { cells } \\
\%\end{array}$ \\
\hline Intrinsic asthma & $60(40-100)$ & $1.6(1.0-7.0)$ & $84(68-99)$ & $3(0-12)$ & $4(0-27)$ & $2(0-12)$ & $0(0-4)$ \\
Extrinsic asthma & $118(40-150)$ & $6.1(1.2-19.6)$ & $96(62-99)$ & $0(0-27)$ & $1.5(0-10)$ & $0.5(0-8)$ & $0(0-3)$ \\
Nonatopic control & $125(100-150)$ & $8.0(1.9-10.5)$ & $98(69-99)$ & $2(0-15)$ & $0(0-8)$ & $0(0-8)$ & $0(0-1)$ \\
Atopic control & $95(45-175)$ & $3.5(1.6-7.4)$ & $97(93-99)$ & $0(0-3)$ & $0(0-1)$ & $2(0-7)$ & $0(0-2)$ \\
\hline
\end{tabular}

Values are expressed as the median, and range in parenthesis.

serum in TBS. Rabbit antibodies (or control rabbit immunoglobulin (IgG)) were applied diluted 1/500 in 1:1 TBS:block solution for $1.5 \mathrm{~h}$ at $37^{\circ} \mathrm{C}$. After washing, biotinylated secondary antibody (Biomen, Berkshire, UK) diluted $1 / 50$ in TBS was applied for $1 \mathrm{~h}$ at $37^{\circ} \mathrm{C}$. Slides were washed, and streptavidin conjugated to alkaline phosphatase (Biomen) applied at a dilution of $1 / 50$ in TBS for $45 \mathrm{~min}$ at $37^{\circ} \mathrm{C}$. Slides were washed for $5 \mathrm{~min}$ in TBS followed by $5 \mathrm{~min}$ in $50 \mathrm{nM}$ levamisole (Biomen). Slides were then flooded with alkaline phosphatase substrate solution (Biomen) and incubated for 2-5 min. The reaction was stopped by immersing in running water. Slides were counterstained for $5 \mathrm{~min}$ with Mayers haematoxylin (Sigma).
RANTES. An alkaline phosphatase anti-alkaline phosphatase (APAAP) technique was used to detect RANTES, following the method of Y YNG et al. [23] with minor modifications. Slides were fixed as above, washed in TBS and then blocked for $2 \mathrm{~h}$ at $37^{\circ} \mathrm{C}$ with $2 \%$ normal goat serum diluted in TBS. Mouse anti-RANTES (R\&D Systems Europe Ltd, UK) or normal mouse IgG control (DAKO, High Wycombe, UK) was applied diluted to $25 \mu \mathrm{g} \cdot \mathrm{mL}^{-1}$ in TBS containing $0.1 \%$ Tween 20 (wash buffer) and the slides incubated at room temperature overnight. Slides were then washed for $5 \mathrm{~min}$, and rabbit anti-mouse immunoglobulins (DAKO) applied diluted $1 / 30$ in wash buffer. Slides were incubated for $30 \mathrm{~min}$ at room temperature, washed, and mouse monoclonal 
APAAP (DAKO), diluted 1/30 in wash buffer, applied for 30 min at room temperature. Rabbit anti-mouse and mouse APAAP steps were repeated three times at 10 min each to enhance staining intensity. After a final wash, slides were flooded with alkaline phosphatase substrate solution (Vector Laboratories Ltd, Peterborough, UK) for 2-5 min. The reaction was stopped by immersion in running water, and slides were counterstained with Mayers haematoxylin (Sigma). All slides were coded and read blind, with comparison to positive and negative controls. A staining intensity score was allotted to each slide as follows: $0=$ no staining; $1=$ weak staining; 2 = moderate staining; and $3=$ strong staining. The cell populations that stained were noted.

\section{Statistical analysis}

Analysis of chemokine levels was carried out using one way analysis of variance (ANOVA) for direct group comparisons. Chi-squared analysis was used for comparison of chemokine levels over an increasing LPS dose. A p-value of less than 0.05 was were considered significant. Regression analyses were performed using the Systat package for Apple Macintosh (Systat Inc., Everston, IL, USA).

\section{Results}

\section{Production of IL-8, RANTES and MCP-1 by BAL cell cultures}

Figures 1-3 show the concentrations of IL-8, RANTES and MCP-1, respectively, in the supernatants of BAL cells from asthmatic and nonasthmatic subjects after $24 \mathrm{~h}$ culture with an increasing dose of LPS. IL-8 production by BAL cells (fig. 1) was significantly elevated in the extrinsic asthma group only, compared with atopic controls $(\mathrm{p}<0.05)$. Only two out of nine intrinsic asthmatics (compared with five out of ten extrinsic asthmatics) showed an increase in IL-8 above control levels. In contrast, RANTES (fig. 2) was elevated in the BAL cell supernatants of intrinsic asthmatics only; four out of nine intrinsic asthmatics showed an increase in RANTES
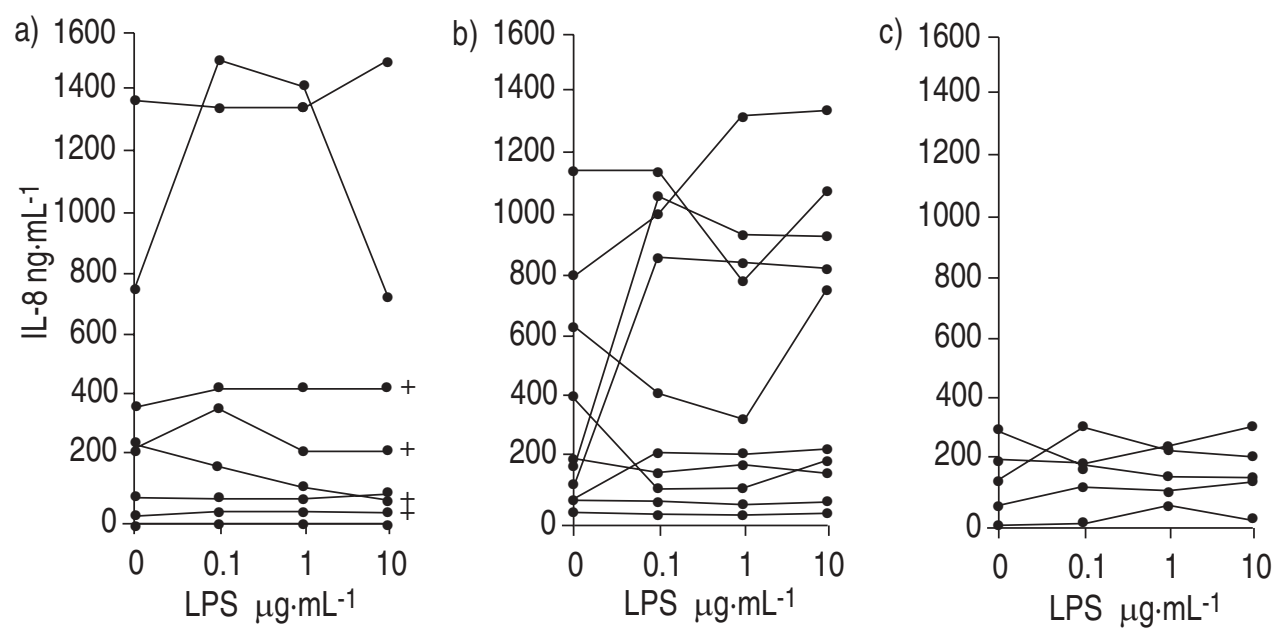

above control levels, but this did not reach statistical significance. There was no significant difference in the production of MCP-1 (fig. 3) by BAL cells between the four groups studied. There was very little evidence of an LPS dose-dependent increase in either IL-8, RANTES or MCP-1. Less than half of the subjects responded to LPS by an increase in chemokine production. In these cultures, $0.1 \mu \mathrm{L} \cdot \mathrm{mL}^{-1}$ LPS appeared to be optimal in most cases.

\section{Immunohistochemical staining of BAL cells for $I L-8$, RANTES and MCP-1}

Figure 4 summarizes the staining intensity score of BAL cell cytospins from individual subjects stained for IL-8 (fig. 4a), RANTES (fig. 4b) and MCP-1 (fig. 4c). These results show a relatively intense staining for IL-8 in both intrinsic and extrinsic asthma groups compared with controls, while the most intense positive stain for RANTES was found in the intrinsic asthma group. Most cytospins stained weakly or moderately for MCP-1 across the four subject groups. However, the largest group of moderately stained samples was in the extrinsic asthma group. This was interesting because no increase in MCP-1 had been identified in BAL cell culture (see above), suggesting the storage, but not secretion, of this chemokine. The cell type staining positive in each case was the macrophage. The few other types of cell that were present (i.e. lymphocytes and neutrophils) were negative.

Regression analyses showed positive correlations between the production of IL-8, RANTES and MCP-1 in BAL cell culture supernatants (in the absence of LPS) and the macrophage staining intensity score for each chemokine $(r=0.765,0.662$ and 0.695 for IL-8, RANTES and MCP-1, respectively). BAL cells were not immunostained for chemokines after the $24 \mathrm{~h}$ culture period. We did not find any other correlations between BAL cell chemokine levels and the proportions of any other cell type present in the BAL. These results support the hypothesis that the macrophage is a major potential source of IL-8, RANTES and MCP-1 in the BAL cell cultures.

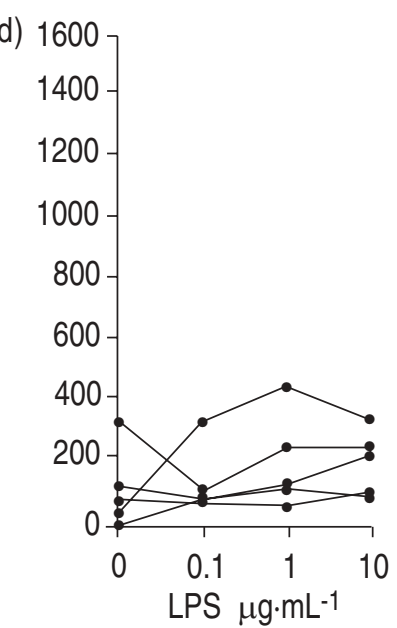

Fig. 1. - Bronchoalveolar lavage (BAL) cell culture supernatant interleukin 8 (IL-8) concentration after $24 \mathrm{~h}$ in the presence or absence of lipopolysaccaride (LPS) $\left(0,0.1,1\right.$ and $\left.10 \mu \mathrm{g} \cdot \mathrm{mL}^{-1}\right)$. IL-8 was elevated in: a) two out of nine intrinsic asthmatics; b) five out of 10 extrinsic asthmatics, compared with c) nonatopic controls and d) atopic controls, respectively. This represents a significant increase in the case of extrinsic asthma $(\mathrm{p}<0.05)$. Two intrinsic asthmatics showed an IL-8 concentration of 0 at all doses of LPS measured. ${ }^{+}$: patients taking inhaled steroids. 

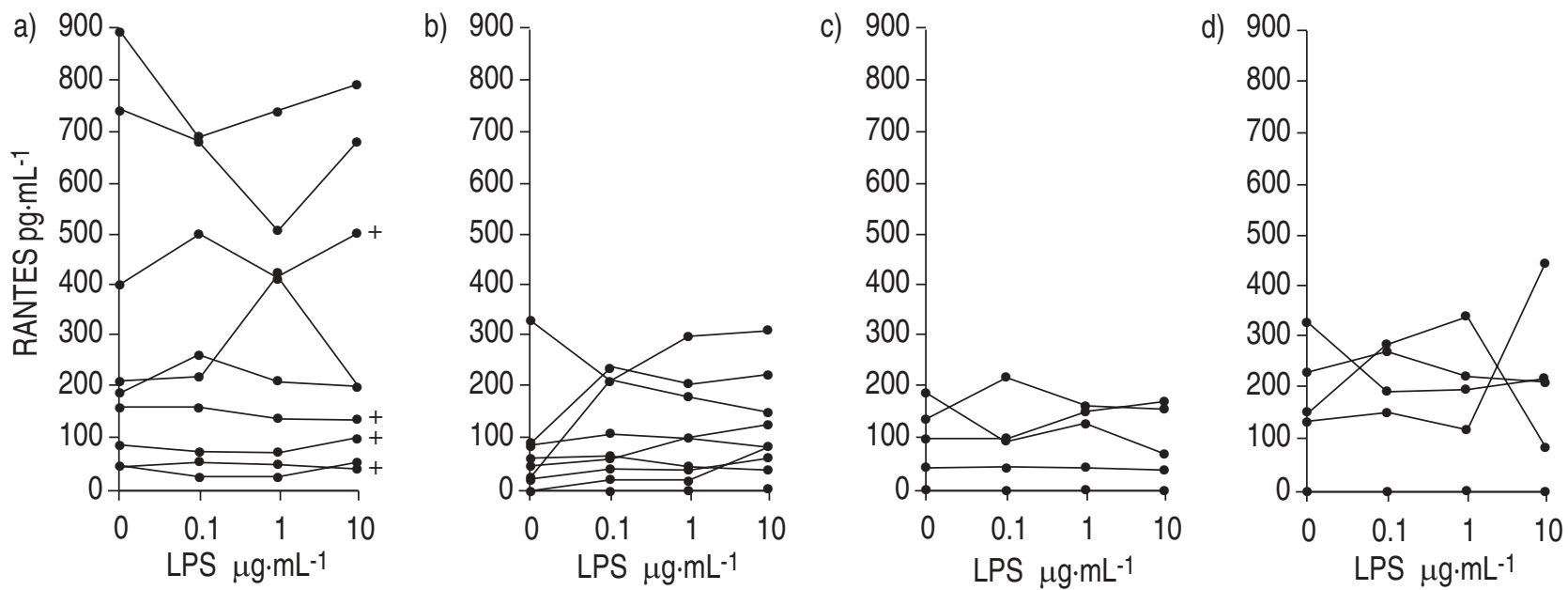

Fig. 2. - BAL cell culture supernatant regulated on activation, normal T-cell expressed and secreted (RANTES) after $24 \mathrm{~h}$ in the presence or absence of LPS $\left(0,0.1,1\right.$ and $\left.10 \mu \mathrm{g} \cdot \mathrm{mL}^{-1}\right)$. RANTES was elevated in: a) four out of nine intrinsic asthmatics (but this did not reach statistical significance), b) RANTES levels in extrinsic asthmatics were all low, in comparison to c) nonatopic controls and d) atopic controls, respectively. + : patients taking inhaled steroids. For definitions see legend to figure 1.
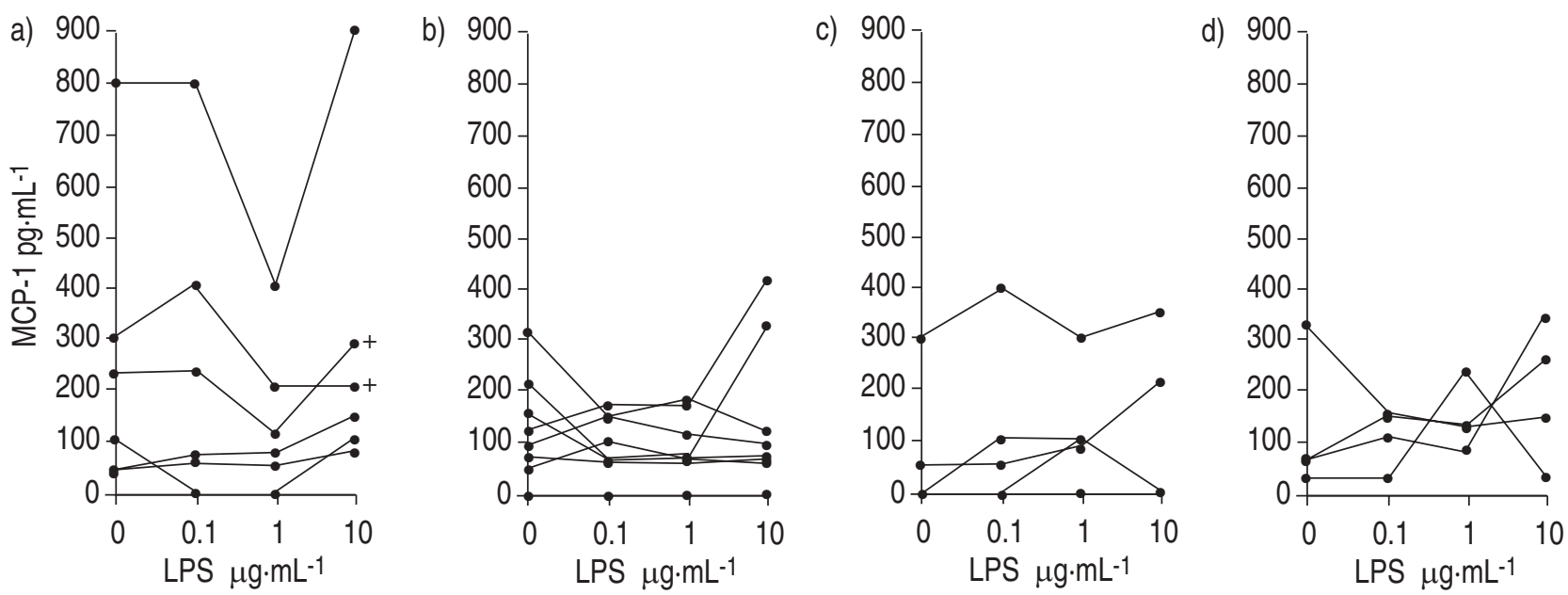

Fig. 3. - BAL cell culture supernatant monocyte chemotactic protein-1 (MCP-1) after $24 \mathrm{~h}$ in the presence or absence of LPS $(0,0.1,1$ and $10 \mu \mathrm{g} \cdot \mathrm{mL}^{-1}$ ): a) intrinsic asthma; b) extrinsic asthma; c) nonatopic control; d) atopic control. One out of six nonatopic asthmatics tested for MCP-1 showed an increase above control levels, but no statistically significant differences were found between the four groups. ${ }^{+}$: patients taking inhaled steroids. For definitions see legend to figure 1.
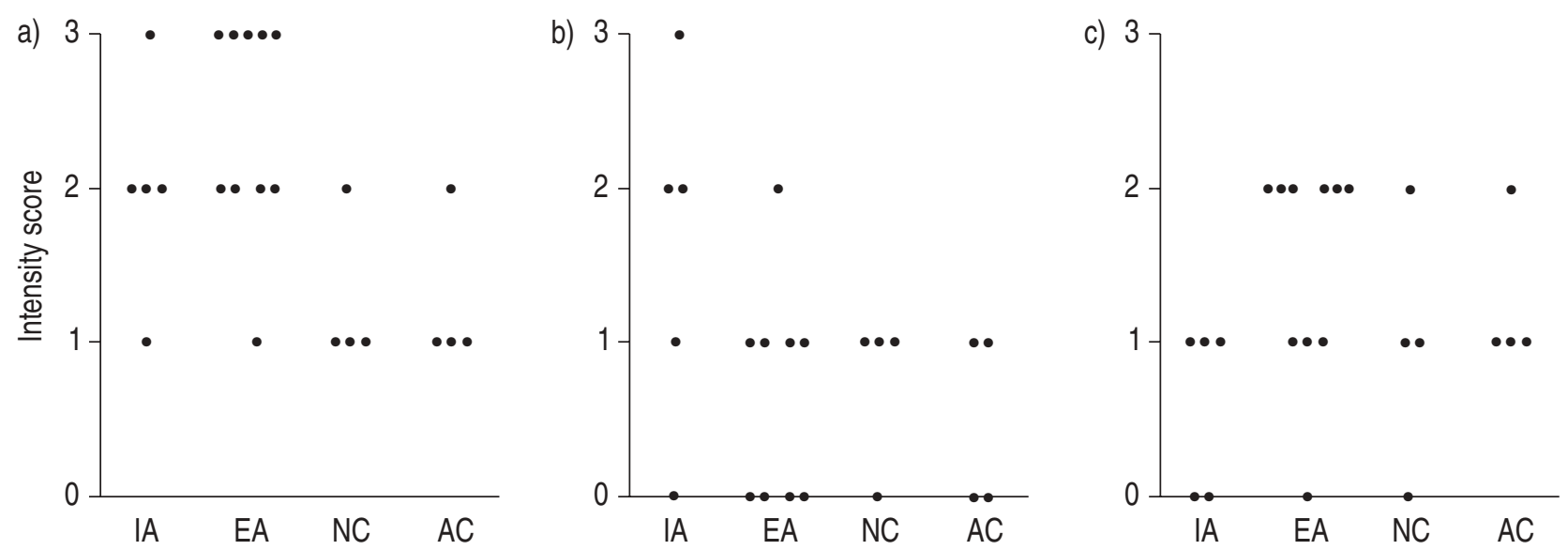

Fig. 4. - Immunohistochemical staining intensity scores of individual BAL cell cytospins for: a) IL-8; b) RANTES; and c) MCP-1. All cytospins were found to contain IL-8 positive cells, with asthmatic cytospins staining at a higher intensity relative to controls. The strongest RANTES staining was found in the intrinsic asthma group, while most extrinsic asthma and control cytospins stained relatively weakly or not at all. Most cytospins stained positive for MCP-1, with the largest amount of moderate staining occurring in the extrinsic asthma group. IA: intrinsic asthma; EA: extrinsic asthma; NC: nonatopic control; AC: atopic control. For definitions see legends to figures 1-3. 

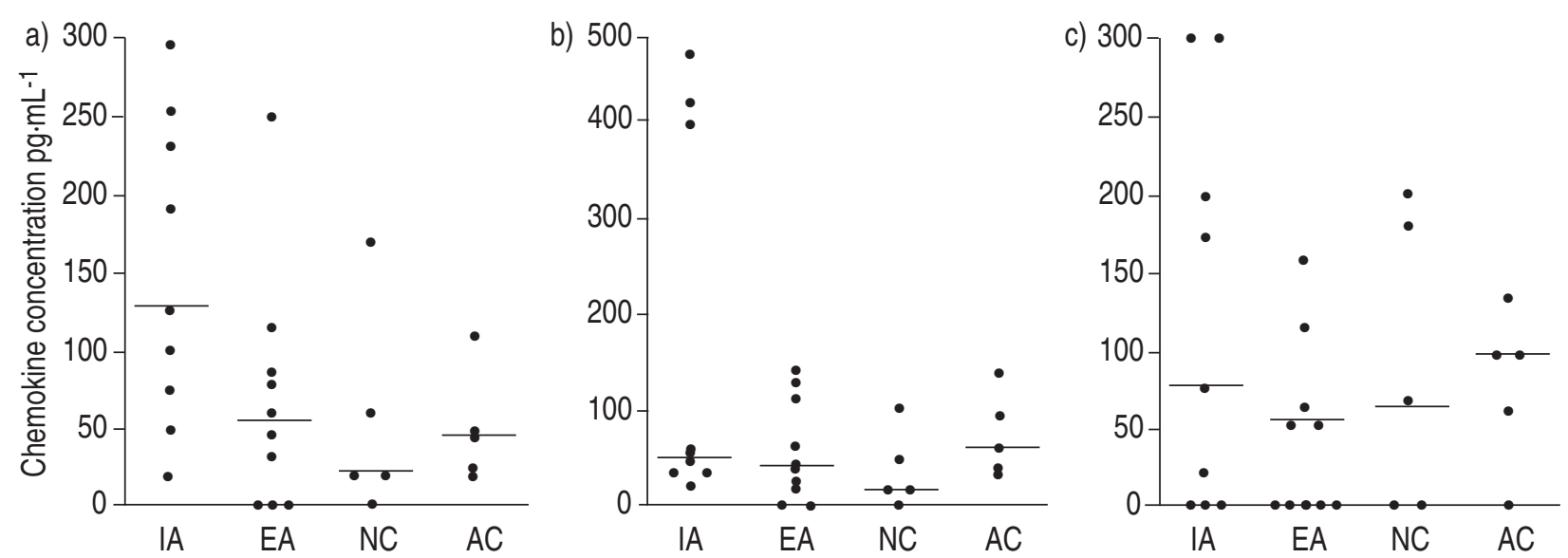

Fig. 5. - Levels of: a) IL-8; b) RANTES; and c) MCP-1 in bronchoalveolar lavage fluid (BALF). IL-8 was significantly elevated in the intrinsic asthma group relative to nonatopic controls $(\mathrm{p}<0.05)$, but no significant increase in IL- 8 was seen in the BALF of extrinsic asthmatics. RANTES was noticeably elevated in three out of nine intrinsic asthmatics, but this did not represent a statistically significant increase for the group as a whole. No differences were found in the levels of MCP-1 between the four groups (bars indicate the median cytokine concentration for each group). For further definitions see legends to figures $1-4$.

\section{BALF IL-8, RANTES and MCP-1}

Figure 5 shows the levels of IL-8 (fig. 5a), RANTES (fig. 5b) and MCP-1 (fig. 5c) in the unconcentrated BALF of asthmatic and control subjects. IL-8 was significantly elevated in the BALF of intrinsic asthmatics compared with control levels $(p<0.05)$, but there was no increase in IL-8 in the extrinsic asthma group. Three out of nine intrinsic asthmatics had noticeably elevated RANTES in their BALF, but this was not statistically significant for the group as a whole. Interestingly, the concentration of RANTES present in the BALF correlated well with the level of RANTES produced by BAL cell cultures $(r=0.741)$, suggesting that the production of RANTES by macrophages in the BAL may be at least partly responsible for the elevated RANTES in the BALF of these asthmatics. In contrast, neither IL- 8 nor MCP-1 in the BALF correlated particularly well with BAL cell culture supernatant concentrations $(r=0.569$ and $r=0.440$ for IL-8 and MCP-1, respectively), indicating that other cells of the airways, for example epithelial cells, may make an equally important contribution to the presence of these two chemokines in BALF.

\section{Discussion}

Our original hypothesis was that the production of chemokines by leucocytes in the airways may contribute to the selective recruitment of inflammatory cells reported in asthma. Furthermore, we suggested that any differences in the immune cell populations recruited to the airways in intrinsic and extrinsic asthma would be reflected in a differential production of chemokines. To study this proposal, we investigated the levels of IL-8, RANTES and MCP-1 protein produced by total BAL cells from intrinsic and extrinsic asthmatics. Total BAL cells were used to better represent the complex inflammatory milieu present in the airways of asthmatics. However, in practice, the differential cell counts showed most of these cells to be macrophages.

An increased production of IL-8 was shown by BAL cells in both intrinsic and extrinsic asthma, significantly so in the case of extrinsic asthma. In contrast, RANTES production was increased above control levels only in BAL cell cultures from intrinsic asthmatics, although not significantly, suggesting that RANTES production by BAL cells may be differentially regulated in intrinsic and extrinsic asthma. MCP-1 production by $\mathrm{BAL}$ cells was not significantly increased above control levels in either intrinsic or extrinsic asthma.

To further identify the cellular source of the chemokines, BAL cell cytospins were immunostained for IL-8, RANTES and MCP-1. The macrophage was the predominant positively stained cell in each case; the small numbers of other cell types present (neutrophils, lymphocytes and epithelial cells) were negative. Moreover, the intensity of macrophage staining on cytospins correlated well with chemokine production in the BAL cell cultures. Our results support a role for the macrophage in the upregulation of IL-8 and RANTES, but probably not MCP-1, in asthmatic airways. Epithelial cells are known to be a source of chemokines, but in this study these cells in the BAL were shed and were not viable.

These findings are similar to published studies that showed an increase in IL-8 [16], but not RANTES [24] in macrophages from the BAL of extrinsic asthmatic individuals. Sousa et al. [17] demonstrated an increased expression of MCP-1 protein by airway epithelial cells in extrinsic asthma, and our results also suggest that cells other than those in the BAL may be responsible for an increased MCP-1 production in asthma.

The results of chemokine levels in BALF conflicted with those of other workers [25] who have recently demonstrated a significant increase in both RANTES and MCP-1 in 10 fold-concentrated BALF from extrinsic asthmatics. As the effects of concentrating BALF, with regard to other components that may be present in the BALF, are not fully understood, we preferred to use unconcentrated BALF in our assays. We did not find any increase in MCP-1 above control levels, and saw an increase in RANTES only in the intrinsic asthma group, but this was not significant. However, IL-8 was significantly elevated in the BALF from intrinsic asthmatics.

The initial division of the chemokines into $\alpha$ and $\beta$ subfamilies is now realized to be an over-simplification, 
as more and more functions are ascribed to each chemokine. IL-8, RANTES and MCP-1 all have the potential to participate in inflammatory allergic and asthmatic responses, because all have the capacity to attract those cell populations involved. All have been shown to attract both CD4+ and CD8+ T-lymphocytes [11, 12, 14], IL-8 will also attract primed basophils and eosinophils [26], and RANTES, a potent chemoattractant for eosinophils [18], can cause histamine release from basophils [27] and selectively enhance IgE production by B-cells [28]. Chemokines have also recently been shown to induce the attachment of T-lymphocytes to those adhesion molecules that are vital for leucocyte recruitment and migration to occur [10, 29]. Therefore, the role of chemokines in asthma is probably more to do with a complex system of leucocyte networking than the attraction of single cell types.

A number of asthmatic subjects in our study were using inhaled steroids (four out of nine intrinsic asthmatics), which have been shown to affect the production of chemokines. Kwon et al. [30] recently described the inhibition by dexamethasone of RANTES messenger ribonucleic acid (mRNA) and protein production by stimulated human lung epithelial cells in vitro, and the local production of both IL-8 and RANTES protein in allergen-challenged rhinitic subjects has been shown to be inhibited by pretreatment with topical beclomethasone diproprionate [31]. These reports suggest that the differences we observed in our study would have been diminished by the effect of steroids as suggested in figures 1-3.

Our study compared atopic and nonatopic asthmatics with atopic and nonatopic controls. We were, therefore, confident that any differences found were the result of asthma rather than co-existing atopy. One of the measures of atopy used in our study was total plasma IgE antibody levels, which may contribute to the pathology of airways disease [32]. Studies on the role of total IgE in airways disease are inconclusive, however, with the most recent report [33] of a longitudinal study of 1,078 individuals showing no relationship between total serum IgE concentrations and spirometric indices in those people who had never smoked. We found no significant differences in the levels of total IgE between atopic and nonatopic subjects (with or without asthma) in our study population. Furthermore, no correlations were found between the level of total plasma $\operatorname{IgE}$ antibody and either forced expiratory volume in one second (FEV1), age or reactivity to skin-prick allergens. The return of BALF in the intrinsic asthma group was less than that from those patients with extrinsic disease, which may suggest that intrinsic asthmatics have more small airways disease. However, the number of cells per millilitre of BALF, the differential counts and estimates of disease severity were comparable in both groups of patients.

Differences between intrinsic and extrinsic asthma are often thought to be connected with age, since intrinsic asthma, also known as late-onset asthma, tends to occur mainly in older people, while extrinsic asthma is found in the relatively young. In our study, there was no difference in the age range of intrinsic and extrinsic asthmatic groups. Similarly, the age range of both control groups was the same. The age ranges of both asthma groups slightly exceeded those of their relevant control groups, but by a similar amount. Age was not, therefore, an obvious variable in this particular study.

In conclusion, the present study has investigated the possible differences in chemokine production between intrinsic and extrinsic asthma. Many reports investigating the immunology of intrinsic and extrinsic asthma question whether they represent two distinct conditions [34]. TANG et al. [35] have investigated the production of interleukin- 5 by both bronchoalveolar lavage and peripheral blood mononuclear cells from atopic and nonatopic asthmatic and control subjects. They found no significant difference between spontaneous production of interleukin-5 protein from BAL cells of atopic and nonatopic asthmatics, but an increase in response to house dust mite antigen was only seen in the atopic subjects (asthmatic and control). Humbert et al. [36] have examined bronchial biopsies from intrinsic and extrinsic asthmatics for the presence of interleukin-4 and interleukin-5 (messenger RNA and protein), and found no difference between the two groups. The production of interleukin-4 in intrinsic asthma conflicts with other published data [7] and did not correlate with clinical parameters [36]. These data reflect the importance of differentiating between asthma and atopy, but eosinophilic inflammation is a universal pathological feature of asthma, so the baseline production of interleukin-5 as a distal immune response in both atopic and nonatopic subjects might be anticipated.

In the present study, we have looked at a novel aspect of this controversy at a more proximal point in the immune response. The data generated support the view that chemokines have a role in the recruitment of inflammatory cells in asthma, and that differential production occurs in intrinsic and extrinsic asthma, suggesting that they are distinct immunopathological entities.

Acknowledgements: The authors would like to thank A. Hann of Southmead Hospital Clinical Investigation Unit, for conducting all bronchial challenge and skin-prick allergy tests, and R.M. Strieter and M. Burdick of the University of Michigan, USA, for antibodies used in immunostaining procedures and for useful advice and comments.

\section{References}

1. Seminario M-C, Gleich G. The role of eosinophils in the pathogenesis of asthma. Curr Opin Immunol 1994; 6: 860-864.

2. Poston RN, Chanez P, Lacoste JY, Litchfield T, Lee $\mathrm{TH}$, Bousquet J. Immunohistochemical characterisation of the cellular infiltration in asthmatic bronchi. Am Rev Respir Dis 1992; 145: 918-921.

3. Bentley AM, Menz G, Storz CHR, et al. Identification of T-lymphocytes, macrophages and activated eosinophils in the bronchial mucosa in intrinsic asthma. Am Rev Respir Dis 1992; 148: 500-506.

4. Wilson JW, Djukanovic R Howarth PH, Holgate ST. Lymphocyte activation in BAL and peripheral blood in atopic asthma. Am Rev Respir Dis 1992; 145: 958-960.

5. Virchow J-C, Kroegel C, Walker C, Matthys H. Cellular and immunological markers of allergic and intrinsic bronchial asthma. Lung 1994; 172: 313-334.

6. Walker C. The immunology of extrinsic and intrinsic asthma. Agents Actions Suppl 1993; 43: 97-106. 
7. Walker C, Bode E, Boer L, Hansell TT, Blaser K, Virchow J-C. Allergic and non-allergic asthma have distinct patterns of T-cell activation and cytokine production in peripheral blood and BAL. Am Rev Respir Dis 1992. 146: 109-115.

8. Tang MLK, Coleman J, Kemp AS. IL-4 and IFN- $\gamma$ production in atopic and nonatopic children with asthma. Clin Exp Allergy 1995; 25: 515-521.

9. Walker C, Virchow J-C, Iff T, Bruijnzeel PLB, Blaser $\mathrm{K}$. T-cells and asthma. 1. Lymphocyte sub-populations and activation in allergic and nonallergic asthma. Int Arch Allergy App Immunol 1991; 94: 241-243.

10. Schall TJ, Bacon KB. Chemokines, leukocyte trafficking and inflammation. Curr Opin Immunol 1994; 6 : 865-873.

11. Larsen CG, Anderson AO, Appella E, Oppenheim JJ, Matsudhima K. The neutrophil-activating protein (NAP1) is also chemotactic for T-lymphocytes. Science 1991; 243: 1464-1466.

12. Taub DD, Proost P, Murphy WJ, et al. Monocyte chemotactic protein-1 (MCP-1), -2 and -3 are chemotactic for human T-lymphocytes. J Clin Invest 1995; 95: 1370-1376.

13. Schall TJ, Bacon K, Toy KJ, Goeddel DV. Selective attraction of monocytes and T-lymphocytes of memory phenotype by cytokine RANTES. Nature 1990; 347: 669-671.

14. Murphy WJ, Taub DD, Anver M, Oppenheim JJ, Kelvin DJ, Longo DL. Human RANTES induces the migration of human T-lymphocytes into the peripheral tissues of mice with severe combined immunodeficiency. Eur $J$ Immunol 1994; 24: 1823-1827.

15. Baggiolini M, Dahinden CA. CC chemokines in allergic inflammation. Immunol Today 1994; 15(3): 127-133.

16. Hallsworth MP, Soh CP, Lane SJ, Arm JP, Lee TH Selective enhancement of GM-CSF, TNF-alpha, IL-1 $\beta$ and IL-8 production by monocytes and macrophages of asthmatic subjects. Eur Respir J 1994; 7(6): 1096-1102.

17. Sousa AR, Lane SJ, Nakhosteen JA, Yoshimura T, Lee $\mathrm{TH}$, Poston RN. Increased expression of the monocyte chemotactic protein-1 in bronchial tissue from asthmatic subjects. Am J Respir Cell Mol Biol 1994; 10: 142-147.

18. Alam R, Stafford S, Forsdythe P, Harrison R, Faubion D, Lett-Brown M, Grant J. RANTES is a chemotactic and activating factor for human eosinophils. J Immunol 1993; 150: 3442-3448.

19. ATS Board of Directors. Standards for the diagnosis and care of patients with chronic obstructive pulmonary disease (COPD) and asthma. Am Rev Respir Dis 1986; 136: 225-244.

20. Aas K. Heterogeneity of bronchial asthma: sub-populations, or different stages of disease? Allergy 1981; 36: 3-14.

21. Goldstein RA. Summary and recommendations of a workshop on the investigative use of fibreoptic bronchoscopy and BAL in asthmatics. Am Rev Respir Dis 1985; 132: 180-182.

22. Paine R, Rolfe MW, Standiford TJ, Burdick MD, Rollins BJ, Strieter RM. MCP-1 expression by rat type
II alveolar epithelial cells in primary culture. J Immunol 1993; 150(10): 4561-4570.

23. Ying S, Meng Q, Taborda-Barata L, et al. Human eosinophils express mesenger RNA encoding RANTES and store and release biologically-active RANTES protein. Eur J Immunol 1996; 26(1): 70-76.

24. Sarno M, Berkman N, Sethi S, Spiteri MA. RANTES production following in vitro allergen challenge in asthmatic subjects. Am J Respir Crit Care Med 1995; 151(4): A783.

25. Alam R, York J, Boyars M, et al. Increased MCP-1, RANTES and MIP- $1 \alpha$ in BAL of allergic asthmatic patients. Am J Respir Crit Care Med 1996; 153: 1398-1404.

26. Dahinden CA, Geiser T, Brunner T, et al. Monocyte chemotactic protein-3 is a most effective basophil and eosinophil activating chemokine. J Exp Med 1994; 179(2): 751-756.

27. Kuna P, Reddigari SR, Schall TJ, Rucinski D, Viksman MY, Kaplan AP. RANTES, a monocyte and T-lymphocyte chemotactic cytokine releases histamine from human basophils. J Immunol 1992; 149(2): 636-642.

28. Kimata H, Yoshida A, Ishioka C, Fujimoto M, Lindley I, Furusho K. RANTES and macrophage inflammatory protein $1 \alpha$ selectively enhance immunoglobulin (IgE) and $\mathrm{IgG} 4$ production by human B-cells. J Exp Med 1996; 183: 2397-2402.

29. Lloyd AR, Oppenheim JJ, Kelvin DJ, Taub DD. Chemokines regulate $\mathrm{T}$-cell adherence to recombinant adhesion molecules and extracellular matrix proteins. J Immunol 1996; 156: 932-938.

30. Kwon OJ, Jose PJ, Robbins RA, Schall TJ, Williams TJ, Barnes PJ. Glucocorticoid inhibition of RANTES expression in human lung epithelial cells. Am J Respir Cell Mol Biol 1995; 12: 488-496.

31. Sim TC, Reece LM, Hilsmeier KA, Grant JA, Alam R. Secretion of chemokines and other cytokines in allergen-induced nasal responses; inhibition by topical steroid treatment. Am J Respir Crit Care Med 1996; 152: 927-933.

32. Dow L. Desperately seeking a solution - total serum immunoglobulin E and airways obstruction. Clin Exp Allergy 1995; 25: 370-376.

33. Shadick NA, Sparrow D, O'Connor GT, DeMolles D, Weiss ST. Relationship of serum IgE concentration to level and rate of decline of pulmonary function: the normative aging study. Thorax 1996; 51: 787-792.

34. Kroegel C, Jager L, Walker C. Intrinsic asthma: a distinct immunopathological entity? Eur Respir J 1997; 10: 513-515.

35. Tang C, Rolland JM, Ward C, Quan B, Walters EH. IL-5 production by bronchoalveolar lavage and peripheral blood mononuclear cells in asthma and atopy. Eur Respir J 1997; 10: 624-632.

36. Humbert M, Durham SR, Ying A, et al. IL-4 and IL-5 mRNA and protein in bronchial biopsies from patients with atopic and nonatopic asthma: evidence against "intrinsic" asthma being a distinct immunopathologic entity. Am J Respir Crit Med 1996; 154: 1497-1504. 